\title{
Stroke patients' experience with the Australian health system: A qualitative study
}

\author{
Jennifer H. White - Parker Magin - Michael R. P. Pollack
}

\section{Key words}

- Outcomes | Post-stroke depression - Cerebrovascular accident | Qualitative research

\section{Mots clés}

- Résultats - Dépression à la suite d'un accident vasculaire cérébral = Accident vasculaire cérébral

- Recherche qualitative

\begin{abstract}
Background. Consumer feedback about experiences with the health system is integral to service planning and is consistent with growing interest in patient-centred care. Purpose. To explore the experiences of community-dwelling stroke survivors at one, three, and five years using a community-based, cross-sectional study. Methods. The quantitative study was comprised of 90 participants post-stroke (3 cohorts, each including 30 participants). Qualitative interviews were undertaken with 12 participants (4 participants from each cohort). This paper presents findings from the qualitative component of the project. Findings. The majority of participants in each cohort were independent and a high proportion required community services. Qualitative data identified varied experiences with the health system, including knowledge about stroke, communication with the health system, and influences on transition home. Implications. The results presented identify the need for ongoing health professional education to enhance stroke service delivery. There is a particular need to address stroke risk-factor modification and to ensure close collaboration with patients and other health professionals with regard to rehabilitation processes. Results identify experiences with health systems up to five years post-stroke. Occupational therapy can play an essential role in post-stroke education and in rehabilitation focused on adjustment to stroke.
\end{abstract}

\section{Résumé}

Description. Les commentaires des consommateurs sur les expériences qu'ils ont vécues face au système de santé font partie intégrante de la planification des services et témoignent de l'intérêt croissant pour les soins centrés sur le patient. But. Examiner les expériences vécues par des survivants d'un accident vasculaire cérébral (AVC) vivant dans la collectivité un an, trois ans et cinq ans après leur AVC, à partir d'une étude transversale à base communautaire. Méthodologie. Létude quantitative regroupait 90 participants ayant subi un accident vasculaire cérébral (3 cohortes comprenant chacune 30 participants). Des entrevues qualitatives ont été menées auprès de 12 participants (4 participants de chaque cohorte). Cet article présente les résultats de la composante qualitative du projet. Résultats. La majorité des participants de chaque cohorte étaient autonomes et une forte proportion avaient besoin de services communautaires. Les données qualitatives ont permis de déterminer que les participants avaient vécues des expériences variables face au système de santé, notamment face à la transmission de connaissances sur les AVC, à la communication au sein du système de santé et aux facteurs influant sur la transition vers le domicile. Conséquences. Les résultats présentés permettent de cibler le besoin de formation continue chez les professionnels de la santé en vue de rehausser la prestation des services offerts aux personnes ayant subi un AVC. Les résultats indiquent aussi le besoin particulier d'aborder la modification du facteur de risque de l'AVC et de s'assurer d'une étroite collaboration avec les patients et les autres professionnels de la santé, en ce qui concerne les processus de réadaptation. Les résultats indiquent que les participants ont eu des expériences avec les systèmes de santé jusqu'à cinq ans après leur AVC. L'ergothérapie peut jouer un rôle essentiel dans l'éducation relative aux AVC et dans la réadaptation centrée sur l'adaptation à la suite d'un AVC.

S troke is one of the leading causes of long-term disability in the Australian population and the second leading cause of death (Australian Institute of Health and Welfare [AIHW], 2004; National Stroke Foundation [NSF], 2007). It has been well documented that organised multidisciplinary rehabilitation programs in acute and post-acute settings result in reduced dependency after stroke (Sinha \& Warburton, 2000). Most stroke survivors will return to living in the community, with only $12 \%$ requiring admission to more supported care such as residential care facilities (AIHW). Studies show that by the end of the first year about half of all stroke survivors will remain dependent on others for activities of daily living (Dewey et al., 2002; Hankey, Jamrozik, Broadhurst, \& Anderson, 2000) and experience ongoing handicap (Sturm et al., 2004). For many people, the need for transition to residential care may be averted by the availability of comprehensive support and the continuity of services in the community. 
An understanding of the experiences of stroke survivors, including feedback regarding patients' experiences with the health system, is integral to the ongoing development of improved stroke services. This is likely to result in enhanced patient-centred practice, which has been shown to improve patient satisfaction and outcomes in occupational therapy settings (Law, Baptiste, \& Mills, 1995). Patient-centred care requires close collaboration between the patient and health professional and is underpinned by respect shown to patient values and choices (Hammell, 2006).

Patient-centred practice is central to the principles guiding occupational therapy practice. Occupational therapists can assist stroke survivors in maintaining physical and emotional health by equipping them with skills to support continued engagement in meaningful occupations (Wilcock, 1998; Zemke \& Clark, 1996). This requires a close working relationship between the patient and clinician in order to identify and prioritise goals that the patient establishes (Law et al., 1995). Patient involvement in the rehabilitation process can be hard to measure. Qualitative methodology provides a means for achieving an understanding of patients' attitudes and experiences (Grbich, 2007) and is appropriate to explorations of the patient-health service interface. In recent decades, several qualitative studies have attempted to understand barriers to patient involvement by exploring the perspective of the stroke survivor during the rehabilitation process. These have demonstrated differences in patient priorities as compared to health professional priorities (McKevitt, Redfern, Mold, \& Wolfe, 2004). Studies involving health professionals have demonstrated a tendency to focus on physical tasks in preference to those stroke survivors value: those that facilitate resumption of their prestroke life styles and help them to maintain their former identities (Doolittle, 1991; Kauffman, 1998).

Previous qualitative research has demonstrated the complexity of the the stroke survivor's experience, including response to stroke onset (Yoon \& Byles, 2002), coping strategies (Pound, Gompertz, \& Ebrahim, 1998), difficulties understanding information provided by the health system about stroke (Wiles, Pain, Buckland, \& McLellan, 1998), and the experience of altered functioning (Alaszewski, Alaszewski, \& Potter, 2004; O'Connell et al., 2001). A study by Pound, Bury, Gompertz, and Ebrahim (1995) found that patients felt their needs were met during hospital admission. However, other studies indicate that stroke survivors have ongoing, unmet needs within the few months following discharge (Pound et al.). There has, however, been limited exploration of the experience of stroke survivors beyond the first few months and this has resulted in a significant evidence gap.

To address this evidence gap, we studied communitydwelling stroke survivors at one, three, and five years poststroke in the Hunter region, New South Wales, Australia. Our mixed methods study comprised two stages. Quantitative (stage one) and qualitative (stage two) methodologies were used. The hypothesis for Stage One was that over time people learn to adapt and cope with stroke. It was hypothesized that after stroke there would be an improvement in post-stroke functioning and mood with increasing time after stroke. The aim of stage two was to explore the experiences of communitydwelling stroke survivors with the local health system.

In summary, the results in stage one revealed that, contrary to our hypothesis, stroke survivors' function is not significantly different at the three time points sampled. Participants demonstrated minimal cognitive impairment and reported high levels of perceived social support. A surprising result was the extent of mood disturbance that participants experienced despite reasonable recovery. A high proportion of survivors required continuing community services at three and five years post-stroke. These included assistance inside and outside the home. Physiotherapy and podiatry services were the most commonly accessed allied health services (White, Alston, et al., 2007).

The current paper reports qualitative findings (exploring stroke patients' experiences with the health system) from this mixed methods study. We have previously reported the extent of altered functioning (White, Magin, Mackenzie, \& Pollack, 2008) and mood disturbance (White, Magin, Attia et al., 2008) from the qualitative stage of the study.

\section{Methods}

This study used a mixed-methods approach involving a cross-sectional study of three retrospective cohorts and qualitative interviews.

\section{Recruitment \\ Stage one: Retrospective cohort}

The study assembled three retrospective cohorts, each comprised of 30 participants:

- Cohort 1: People who had had a stroke 1 year prior to recruitment.

- Cohort 3: People who had had a stroke 3 years prior to recruitment.

- Cohort 5: People who had had a stroke 5 years prior to recruitment.

The data source was hospital records/separation from principle tertiary referral and teaching hospital servicing Hunter residents. Inclusion criteria were admission to hospital, alive at discharge, and history and examination consistent with stroke as determined by a stroke physician. Consecutive patients admitted for stroke from the start of January 2000, 2003, and 2005 were contacted via mail-out, commencing in January 2006, until 30 participants were recruited for each cohort. Exclusion criteria were severe cognitive impairment (as determined by the Mini-Mental State Examination [Folstein, Folstein, \& McHugh, 1975]) and 
inability to give informed consent, and current residence in a nursing home, that is, only community-dwelling stroke survivors (including hostels) were contacted. There was no substantive change in health service organisation or clinical practice regarding post-stroke care in the region in which the study was performed during the five years prior to the study.

\section{Stage two: Qualitative interviews}

The qualitative component involved semi-structured interviews with 12 stroke survivors at one, three, and five years after stroke.

Sampling in qualitative research involves identifying participants who can provide insight into the specific and personal experiences to be examined rather than obtaining a representative sample, as would be sought in a quantitative study. Purposive, maximum variation sampling was undertaken in this study to identify men and women of different ages and with different living arrangements so as to reach as heterogeneous a sample as possible (Strauss \& Corbin, 1998). All participants in the quantitative study were invited to participate in the subsequent qualitative study and provide simple additional demographic information, such as living arrangement and receipt of community services.

Thirty-seven participants from stage one consented to participate in semi-structured interviews. Twelve people were initially selected for interview, 4 from each cohort. The number of participants selected for interview is in line with previous qualitative research producing thematic saturation (Strauss \& Corbin, 1998). There was a provision for further sampling and further interviews if required to achieve thematic saturation, but saturation (as assessed by the emergence of no new codes or themes in the final three interviews) was achieved in the initial 12 interviews.

\section{Procedures}

Stage one: Cross-sectional study

During stage one, demographic, stroke subtype, and comorbidity data were collected from hospital records to make it possible to compare participants and the three cohorts. Stroke subtype was established, and level of disability, cognitive status, stroke-specific function, and perceived social support were all assessed by means of validated instruments.

\section{Stage two: Qualitative interviews}

The primary author conducted a single interview with each of the 12 participants. A modified grounded theory approach was used to facilitate generation of concepts that would increase understanding of the post-stroke experience (Grbich, 2007). A modified grounded theory approach incorporates data collection, coding, and analysis using a process of constant comparison but without a theory development component (Bogdan \& Biklen, 1998; Pope, Ziebland, \& Mays, 1995). This entails an ongoing cycle of data collection and simultaneous analysis to inform ongoing data collection.

A schedule of questions (Appendix 1) was used for the interviews. However, the iterative (altering the research methods and the hypothesis as the study progresses [Greenhalgh \& Taylor, 1997]) nature of a semi-structured interview format meant that discussion was not limited to predetermined areas of inquiry.

All participants elected to be interviewed in their own homes. The duration of the qualitative interviews ranged from 45 minutes to 90 minutes. Each interview was recorded with the permission of the participant. To create a comfortable atmosphere, the interviewer began by asking each participant to describe the "story" of the onset of stroke and his or her life before the stroke. Subsequent questions explored post-stroke lifestyle and experiences with the health system.

\section{Qualitative interviews}

\section{Data analysis}

All interviews were transcribed verbatim, with identifying data removed, and the transcripts conceptualised and coded. The first step of the coding process was open coding, which involved a literal line-by-line reading and interpretation of the transcripts to identify a wide range of categories from the data. These categories were given a label or code consisting of four letters in order to facilitate retrieval between the transcripts (for example, communication issues were labeled as COMC). This data analysis involved a process of constant comparison whereby new data were aligned with existing codes and new codes generated. Thus, later interviews accommodated questioning on codes and concepts emerging from the preceding interviews and identified in the coding process.

The next level of analysis was axial coding, which involved identifying relationships between codes and the grouping of codes into coherent categories. The final level of analysis involved the iterative mapping of codes (concurrent with the process of constant comparison) and the identification of major categories and their relationships and interactions (Pope et al.,1995). Further examination at this level of interaction between stroke survivors and health services provided the basis for this paper.

Two researchers undertook consensus coding (J. W. and P. M.). Consensus was gained via extensive discussion of the codes and how they were developed during data analysis. Consensus coding was conducted concurrently with data collection. Consensus coding has been proposed to increase reliability and rigor (Pope et al., 1995) and to enrich conceptual analysis (Barry, Britten, Barber, Bradley, \& Stevenson, 1999), especially in the case of analysis by researchers from differing professional backgrounds (Pope et al.). The researchers in this study were an occupational therapist (J. W.), and a physician (P. M.). Consensus coding 
included extensive consideration of evidence for systematic differences in the responses of participants from the three cohorts (that is, differences between respondents sampled at one, three, and five years post-stroke).

Trustworthiness of our data was achieved using several strategies, including immersion in data; reflexive analysis, whereby the researchers critically appraised their relationship with the data and the study context, taking into account any preconceptions (Krefting, 1991; Lincoln \& Guba, 1985), including the preconceptions inherent in the researchers' clinical status and experience; peer debriefing, which ensured that the researchers remained open to the data and did not demonstrate bias during the data analysis (Lincoln \& Guba); and member checking (Creswell, 1994; Glaser \& Strauss, 1967). Member checking involved the mailing of transcripts, with a summary of the transcript interpretations, to participants so they could review them and add or remove any information from their transcripts. Because of potential cognitive and communication difficulties on the part of the participants, the researchers contacted them by phone within a few weeks of receiving the returned transcripts to clarify their feedback. However, the participants did not make any changes to the transcripts or their interpretation.

\section{Ethics}

Ethics Committee approval for this project was obtained from Hunter New England Human Ethics Research Committee.

\section{Results \\ Stage one: Observational descriptive retrospective cohort}

\section{Demographics}

Table 1 compares the key demographics of participants within each cohort. There were no significant differences between cohorts for gender, presence of a caregiver, living situation, marital status, first-ever stroke, ethnicity, dysphasia, and Oxfordshire Community Stroke Project classification (OCSP). There were no significant differences in gender, age, or stroke subtype between participants and nonrespondents (data not shown).

\section{Stage two: Qualitative interviews}

The demographics of the 12 participants are outlined in Table 2. All the participants had experienced an ischaemic stroke, and equal numbers of men and women were interviewed. Information on participant functioning, according to the Modified Rankin Scale (MRS), was available to the interviewer (Sulter, Steen, \& De Keyser, 1999). Five participants were classified as dependent following their stroke and 7 were independent. Ages ranged from 43 to 92 years. We have previously described changes in functioning (White, Magin, Mackenzie, et al., 2008) and mood (White, Magin, Attia, et al., 2008) experienced by this cohort. Participants
TABLE 1

Key demographic characteristics of retrospective study participants $(n=91)$.

\begin{tabular}{|c|c|c|c|c|}
\hline & $\begin{array}{l}\text { Cohort } 1 \\
(n=30)\end{array}$ & $\begin{array}{l}\text { Cohort } 3 \\
(n=31)\end{array}$ & $\begin{array}{l}\text { Cohort } 5 \\
(n=30)\end{array}$ & $\begin{array}{c}\text { Significance } \\
\text { level }\end{array}$ \\
\hline \multicolumn{5}{|l|}{ Gender } \\
\hline Female & $19(63)$ & $11(37)$ & $14(47)$ & $p=0.128$ \\
\hline Male & $11(37)$ & $20(63)$ & $16(53)$ & \\
\hline \multicolumn{5}{|l|}{ Living } \\
\hline \multicolumn{5}{|l|}{ Situation } \\
\hline Live alone (\%) & $8(27)$ & $7(23)$ & $8(27)$ & $p=0.914$ \\
\hline Not alone (\%) & $22(73)$ & $24(77)$ & $22(73)$ & \\
\hline \multicolumn{5}{|l|}{ Marital Status } \\
\hline Married (\%) & $15(50)$ & $18(58)$ & $16(53)$ & $p=0.095$ \\
\hline Other (\%) & $15(50)$ & $13(42)$ & $14(47)$ & \\
\hline \multicolumn{5}{|l|}{$\begin{array}{l}\text { First ever } \\
\text { stroke }\end{array}$} \\
\hline Yes (\%) & $26(87)$ & $24(77)$ & $21(70)$ & $p=0.295$ \\
\hline No (\%) & $4(13)$ & $7(23)$ & $9(30)$ & \\
\hline \multicolumn{5}{|l|}{ Caregiver } \\
\hline Yes (\%) & $8(27)$ & $12(39)$ & $11(37)$ & $p=0.543$ \\
\hline No (\%) & $22(73)$ & $19(61)$ & $19(63)$ & \\
\hline \multicolumn{5}{|l|}{ Ethnicity } \\
\hline Australian (\%) & $27(90)$ & $24(77)$ & $27(90)$ & $p=0.479$ \\
\hline Other (\%) & $3(10)$ & $7(23)$ & $3(10)$ & \\
\hline \multicolumn{5}{|l|}{ Dysphasia } \\
\hline Yes (\%) & $6(20)$ & $7(23)$ & $6(20)$ & $p=0.960$ \\
\hline No (\%) & $24(80)$ & $24(77)$ & $24(80)$ & \\
\hline \multicolumn{5}{|l|}{ OCSP } \\
\hline \multicolumn{5}{|l|}{ Classification } \\
\hline TACI (\%) & $2(7)$ & $3(10)$ & - & $p=0.183$ \\
\hline LACI (\%) & $12(40)$ & $9(29)$ & $6(20)$ & \\
\hline PACI (\%) & $10(33)$ & $12(39)$ & $13(43)$ & \\
\hline POCI (\%) & $5(17)$ & $2(6)$ & $8(27)$ & \\
\hline SAH (\%) & $1(3)$ & $2(6)$ & - & \\
\hline $\mathrm{ICH}(\%)$ & - & $3(10)$ & $3(10)$ & \\
\hline
\end{tabular}

OCSP indicates Oxfordshire Community Stroke Project; TACI, total anterior circulation infarction; $\mathrm{LACl}$, lacunar infarction; $\mathrm{PACl}$, partial anterior circulation infarction; $\mathrm{POCl}$, posterior circulation infarction; $\mathrm{SAH}$, subarachnoid haemorrhage; $\mathrm{ICH}$, intercerebral haemorrhage

described four main categories of mood change, including feelings of frustration, reduced self-efficacy, dependency, and loss (White, Magin, Attia, et al.). Occupational restrictions were varied and participation was affected in the areas of home maintenance, gardening, sports and service to the community (White, Magin, Mackenzie, et al.).

Participants reported three broad constructs related to experiences with the health system (knowledge about stroke, communication with the health system, and influences on transition home). There were no systematic differences in responses relating to experiences with the health system, either during hospital admission or while community dwelling post-stroke, between the three cohorts. Thus, the responses of all participants will be presented without reference to time elapsed since their strokes. 
TABLE 2

Key demographics of qualitative study participants.

\begin{tabular}{|c|c|c|c|c|c|c|c|}
\hline $\begin{array}{l}\text { Parti- } \\
\text { cipant } \\
\#\end{array}$ & Sex & Age & $\begin{array}{c}\text { Marital } \\
\text { status }\end{array}$ & $\begin{array}{c}\text { Year } \\
\text { since } \\
\text { stroke }\end{array}$ & $\begin{array}{c}\text { Stroke } \\
\text { subtype } \\
\text { OCSP }\end{array}$ & $\begin{array}{l}\text { Disability } \\
\text { level } \\
\text { (MRS) }\end{array}$ & $\begin{array}{r}\text { Cognition } \\
\text { (MMSE) }\end{array}$ \\
\hline 1 & Male & 92 & Widowed & 1 & $\mathrm{PACl}$ & 4 & 28 \\
\hline 2 & Male & 60 & Divorced & 1 & $\mathrm{PACl}$ & 3 & 23 \\
\hline 3 & Female & 66 & Married & 1 & $\mathrm{PACl}$ & 4 & 29 \\
\hline 4 & Female & 78 & Widowed & 1 & $\mathrm{POCl}$ & 3 & 29 \\
\hline 5 & Female & 43 & Married & 3 & $\mathrm{PACl}$ & 2 & 29 \\
\hline 6 & Female & 81 & Widowed & 3 & $\mathrm{TACl}$ & 1 & 28 \\
\hline 7 & Male & 58 & Married & 3 & $\mathrm{PACl}$ & 2 & 30 \\
\hline 8 & Male & 78 & Widowed & 3 & $\mathrm{LACl}$ & 1 & 30 \\
\hline 9 & Female & 74 & Separated & 5 & $\mathrm{PACl}$ & 1 & 28 \\
\hline 10 & Male & 70 & Married & 5 & $\mathrm{LACl}$ & 2 & 29 \\
\hline 11 & Female & 79 & Married & 5 & $\mathrm{LACl}$ & 1 & 28 \\
\hline 12 & Male & 82 & Married & 5 & $\mathrm{POCl}$ & 3 & 30 \\
\hline
\end{tabular}

OCSP indicates Oxfordshire Community Stroke Project; $\mathrm{TACl}$, total anterior circulation infarction; LACl, lacunar infarction; $\mathrm{PACl}$, partial anterior circulation infarction; $\mathrm{POCl}$, posterior circulation infarction; MRS, Modified Rankin Score; MMSE, Mini-mental State Examination

\section{Stroke knowledge}

The theme of "knowledge" around the issue of stroke emerged as a prominent finding. Gaps in participant knowledge about stroke led to feelings of uncertainty when dealing with the health system, fear of future stroke, and feelings of stigmatisation.

There was evidence in the interviews that most participants lacked pre-stroke knowledge of stroke-risk factors and warning signs.

I cannot understand what caused it to happen ... I did not know what a stroke was (Participant 1, male, age 92).

And I really did not notice it. I went down to get a hair cut and as I went to walk down the street I took up all the footpath; I just could not walk. I was lucky to get back home actually. I had no idea how to ring [my wife] to let her know where I was, I could not even remember the phone number (Participant 7, male, age 58).

Poor knowledge of stroke was evidenced by the failure of the majority of participants to respond to their stroke symptoms as an emergency. Many participants continued to conduct their daily activities and postponed seeking medical attention because they perceived it was inconvenient or unnecessary and they thought their symptoms would resolve themselves.

I got up that morning ... I felt just funny ... I thought something was wrong; I filled the day out ... when I came home I [called] the doctor (Participant 11, female, age 79).

I refused to go [to the doctor] because it was the day before my 80th birthday (Participant 12, male, age 82).

Participants within the cohorts remained fearful that they would experience a subsequent stroke and this was "always in the back of my mind" (Participant 11, female, age 79). Though essentially a realistic concern, fear resulted in dysfunctional responses by some participants with close monitoring or avoidance of perceived risk factors-often to the point of impairing quality of life or social interaction. Such responses appeared to correlate with their experiencess of, and interpretations of, their acute strokes.

The young blokes say "have a proper beer," but I am too scared to ... in case something else goes wrong (Participant 2, male, age 60).

After stroke, several participants still questioned whether the onset of their strokes could have been prevented if others had had appropriate knowledge about strokes. For most participants, this pertained to health professionals with whom they had had contact about their health prior to the stroke. In most cases concern was directed towards people whom they considered experts, especially their local general practitioners (family physicians). For example, one participant reported that the general practitioner did not treat a previous, minor stroke as an emergency.

I was falling over and I could not walk straight and I was doing this in the [general practitioner] surgery (Participant 1, male, age 92).

Maybe my GP [general practitioner] could have helped me in the beginning (Participant 9, female, age 74).

The participants also highlighted the lack of knowledge regarding stroke within the broader community. In these cases, the lack of knowledge (in members of the broader community) of stroke, its manifestations, and the sequelae resulted in stigmatization of participants. Stigmatization was seen as a consequence of misconceptions regarding disability and impairment in stroke survivors.

They are a little bit standoffish ... like there is something disease-ridden about you (Participant 3, female, age 66).

I am a loner that way since my stroke ... [because] I think I am talking funny (Participant 10, male, age 70).

\section{Communicating with the health system}

Not only levels of knowledge, but also the transfer of knowledge (that is, "communication") emerged as an important theme in this study. Participants perceived that communication with the health system, and within the health system, was ineffective. It was apparent that many participants experienced frustration caused by gaps in the transfer of knowledge between health professionals involved in their care at both an inpatient and outpatient level (see below). In addition, participants experienced confusion when felt they had received insufficient explanations about their treatment.

The only reason I went to them [outpatient services] was because I was sent to them (Participant 7, male, age 58). 
That is one thing that amazed me in hospital after the stroke; nobody ever worked on my hand, never touched it (Participant 3, female, age 66).

The inadequacy of communication could be seen as compromising participants' confidence in their therapeutic process. Several participants reported feelings of distress and uncertainty about the therapy processes experienced during their rehabilitation. For example one participant was unsure of the rationale for a given therapy task.

I did not find it helpful [sitting on a ball] at all. I was scared I was going to fall. The physiotherapist wanted me to turn my head [while sitting on the ball]. Well, have you ever tried it? I could only do what was comfortable. (Participant 9, female, age 74).

Furthermore, dissatisfaction with communication within the health system suggests areas for improvement in system processes. For example, the lack of communication between various health professionals at triage and in subsequent assessment and management phases of the participants' journey through their hospital admission created frustration. An example is the complaint by one participant of "being asked the same questions by everyone" (Participant 9, female, age 74).

In addition, some participants did not feel adequately informed about their ongoing care once they were discharged. This made if difficult to actively participate in making decisions about their health.

$\mathrm{He}$ [the specialist] was finished with me ... but I was determined to find out more. So, I made my own enquiries (Participant 8 , male age 78 ).

Another participant was distressed about experiencing residual impairments that led to resigning from work. It was evident that communication regarding post-stroke occupational expectations had not been suitably clarified.

I thought I was going really good and then I got involved with Commonwealth Rehabilitation Service [a government return-to-work service], and that sort of made me realise I was not as far progressed as I thought I was (Participant 7, male, age 58).

Dissatisfaction with health services relating to ineffective communication was further compounded by perceived lack of respect from individuals within the health system. For example, one participant's experience of incontinence left him feeling ashamed and undignified.

It [incontinence] is disgusting, just disgusting ... the nurses in the hospital would come in the morning and change the sheets. They made you think you should be ashamed of yourself (Participant 1, male, age 92).

A possible example of lack of effective communication affecting a patient's sense of dignity was a participant's overhearing two staff members discussing her treatment; she found their discussion demeaning. This participant felt that a particular staff member did not want to treat her and was trying to persuade a colleague to conduct the treatment session.

I overheard them ... You are not dead. You might be a little bit slow, but you are not dead (Participant 9, female, age 74).

Again, issues with communication were prominent in the difficulties patients encountered. Not all participants were routinely referred to outpatient therapy following discharge from the hospital setting. While the reasons for this are unclear, some participants felt there was a lack of information on how to access ongoing care. They commonly adopted a passive approach towards this and did not actively seek the support they desired. Participants in each cohort mentioned this experience.

If I was younger, I would be a bit more inclined to [actively seek support]. Yes, if I was younger you would want more help with that (Participant 7, male, age 58).

One participant expressed concerns about the "capabilities" or knowledge levels of community-based staff in dealing with issues specific to stroke. For example, he questioned the appropriateness of considering general practitioners experts in the field of stroke. He found that his GP was unable to provide him with sufficiently detailed information about his stroke or with sufficiently expert management.

They [specialist] said to go back to your GP ... I don't know

if that was a wise idea. He is a lovely guy, don't get me wrong ... but I am not sure that he is at that level as far as stroke victims are concerned (Participant 8 , male, age 78).

Despite the misgivings that some participants expressed, overall participants were satisfied with the community services they received and their outcomes.

Without them I would not have got back to where I was (Participant 7, male, age 58).

\section{Influences on transitions home}

The transition from hospital to community care was problematic for many participants in each cohort. Participants reported that the transition home was characterised by feelings of uncertainty.

You sort of feel a bit lost for a while. You wonder how you are going to cope (Participant 4 , female, age 78).

I thought I'd just come out and be as good as gold. But as soon as I came home I realised that things were different (Participant 6, female, age 81).

The majority of participants expressed an ongoing desire to return to valued activities. The absence of longer term reassessment by allied health staff was apparent as none of the participants had been reviewed following discharge from the therapies they received within the first year after stroke. Those participants who had experienced functional improvements or had identified new goals had no opportunity to access further therapeutic advice. This was linked with further uncertainly about their ability to make 
further functional gains. There was also uncertainty about the availability of services, even many years after stroke.

I would like to know what services were available, you know (Participant 2, male, age 60).

Well, I think I should be made more aware of what is available to me (Participant 6, female, age 81).

\section{Discussion}

This study provides data that facilitate an understanding of the experiences that community- dwelling stroke survivors have with the local health system. Results confirm three key areas arising from participants' journey through the health system that influence perceived recovery: stroke knowledge, communication, and transitions. The availability of supporting quantitative data allows for greater interpretation of data and comparison between cohorts. Qualitative findings give insight into real needs versus unmet needs, which can make significant contributions to occupational therapy practice. Overall, the results support the need for community services that help maintain stroke survivors in the community and promote independence and occupational engagement (Pound et al., 1998).

The primary purpose of this qualitative study was to gain insight into participants' perspectives on their experiences with the heath system. Although interviews were conducted with participants at three different time points post-stroke, preliminary analysis revealed no substantive differences in experiences across the three cohorts. Participants in each cohort experienced concern regarding communication discrepancies. Similarly, it was apparent that communitydwelling stroke survivors felt the need to access ongoing health services in order to maximise community participation and goal achievement, even many years after stroke.

Poor knowledge about stroke was evidenced throughout the phases of care in this study. This is of concern with regards to timely and appropriate access to health services, especially at stroke onset. Previous local studies within the Hunter region have shown gaps in public knowledge in recognising stroke symptoms and the need for early presentation to hospital (White, Magin, Attia et al, 2008; Yoon \& Byles, 2002; Yoon, Heller, Levi, Wiggers, \& Fitzgerald, 2001). Improved community knowledge of stroke risk factors and the initiation of primary and secondary prevention strategies, predominantly by GPs, have been shown to contribute to a marked reduction in stroke incidence. For example, the United Kingdom has seen a $30 \%$ reduction in the incidence of firstever stroke and a 50\% decline in intracerebral haemorrhage over the last 20 years as a result of preventative strategies implemented by GPs (Rothwell et al., 2004). Occupational therapy can play a key role in prevention by providing, education for patients at risk of stroke regarding risk-factor management, and education for stroke survivors to alleviate fear of future stroke through risk-factor modification.

The importance of the relationship between health professionals and consumers is well documented in the literature. The data elicited from this study highlight discrepancies between patient and stroke clinician goals. For many patients, unmet goals are often only evident following discharge from hospital and when attempting to resume their pre-stroke lifestyles. As a result stroke survivors can experience the impact of unresolved goals for many years post stroke. These findings support the need for ongoing community monitoring of participation. Community-based occupational therapists, while providing therapy to assist skill acquisition, should be constantly reviewing patients' priorities and goals for therapy. This is consistent with the delivery of patient-centred care.

There were perceived gaps with regards to various aspects of communication with and within the health system. These problems with communication had the potential to lead to patients' having feelings of uncertainty and anxiety. These require further confirmation in future studies and clarification with health professionals' perceptions, especially given that previous research has demonstrated that patients often don't recall information conveyed to them by the health practitioners and services (Forster et al., 2001; Wiles et al., 1998). A key experience was related to frustration due to insufficient explanation of stroke management processes at an inpatient and outpatient level. Since occupational therapists have a key role in discharge planning, they can be instrumental in monitoring patients' understanding of their ongoing need for information or to ensure comprehensive referral to community services.

Participants highlighted the variation in time it can take to make the transition back to previous roles. These results reinforce the extent of difficulties experienced with successful community re-integration after stroke, which can take up to five years after stroke. Ongoing access to occupational therapy intervention, to facilitate independence and participation in meaningful activity, promotes health in the long-term stroke survivor (Wilcock, 1998; Zemke \& Clark, 1996).

Our findings suggest the need for long-term services such as monitoring, assessment, and therapy to maintain or improve physical and psychosocial function. Participants had a lack of awareness about their potential for recovery or knowledge about the availability and role of rehabilitation services. These experiences appeared to be compounded by the limited availability of systematic re-assessment and access to therapy by the public health system following discharge from hospital. Participants within each cohort continued to experience unmet goals. This supports the need for a model that is flexible in its delivery of services to stroke survivors as their needs change over time. This includes access to continuing therapy, especially since research indicates that clinical improvements occur late after brain injury, even in 
stroke survivors who are considered to have reached a recovery plateau (Hodics, Cohen, \& Cramer, 2006). Once again, this is consistent with the delivery of patient-centred approaches. Such results provide further support for the necessity of community-based occupational therapy to assist with ongoing community participation.

\section{Study strengths}

The major strength of this study is that it recruited two of its three cohorts of patients after a longer time post-stroke than the majority of previous studies. Thus, though not longitudinal in design, this study nevertheless generates unique data on the experiences of Australian stroke survivors with the health system that may be inferred to reflect experiences over time, and it provides a context for further study of patients' experiences post-stroke. A further strength of this study lies in the use of quantitative and qualitative methodology using reliable outcome measures and semi-structured interviews. An objective sampling frame (Stage one) suggests that the information is likely to be reflective of the experience of community-dwelling stroke survivors. The maximum variation sampling of participants with a broad range of experiences during Stage two suggests that the finding of congruent experiences in each of the cohorts is robust.

\section{Study limitations}

The use of a retrospective, observational cross-sectional design limits the ability to make interpretations regarding individuals' changes in post-stroke functioning over time. Survivor bias and selection bias could have affected the findings. The fact that the study excluded people with more severe strokes, such as people in nursing homes, is a limitation to the external validity of the study. Results from this sample source may not readily transferable to the wider stroke population due to the impact of healthy volunteer bias and survivor bias. The interviews, while sampling stroke patients at varying times post-stroke, were conducted crosssectionally rather than longitudinally and do not capture individuals' changes over time. Future research should entail a prospective design involving a larger sample of participants.

\section{Conclusion}

The factors identified help inform priorities for enhancing the capacity of community service interventions. These include improved stroke education, more effective communication, and increased attention to patient preferences in treatment planning. There is an essential role for occupational therapists by their being instrumental in practise improvement. Similarly, these findings support the need for long-term monitoring of the stroke patient. The occupational therapist is the ideal professional to carry out this role by providing therapeutic advice, monitoring of risk-factor management, and promotion of participation after stroke.

\section{Acknowledgements}

The authors would like to thank the Hunter Stroke Service for supporting this study.

\section{Key messages}

- Occupational therapy can play an essential role in post-stroke education and in rehabilitation focused on adjustment to stroke.

- Resources for professional development are essential to maintain skills and enhance effective communication, prevention, and post-stroke care.

- Long-term community services, such as those provided by occupational therapists, addressing the physical and psychosocial barriers to occupational engagement after stroke are needed, including programs for late intervention.

\section{References}

Australian Institute of Health and Welfare. (2004). Heart, stroke and vascular diseases: Australian facts (Series 22, AIHW cat. no. CWD27). Canberra, Australia: Author.

Alaszewski, A., Alaszewski, H., \& Potter, J. (2004). The bereavement model, stroke and rehabilitation, a critical analysis of the use of a psychological model in professional practice. Journal of Disability and Rehabilitation, 26, 1067-1078.

Barry, C. A., Britten, N., Barber, N., Bradley, C., \& Stevenson, F. (1999). Using reflexivity to optimize teamwork in qualitative research. Qualitative Health Research, 9, 26-44.

Bogdan, R., \& Biklen, S. (1998). Qualitative research in education: An introduction to theory and methods (3rd ed.). Boston: Allyn \& Bacon.

Creswell, J. W. (1994). Research design: Qualitative and quantitative approaches. Thousand Oaks, California: Sage Publications.

Dewey, H. M., Thrift, A. G., Mihalopoulos, C., Carter, R., Macdonell, R. A. L., McNeil, J. J., et al. (2002). Informal care for stroke survivors: Results from the North East Melbourne Stroke Incidence Study (NEMESIS). Stroke, 33, 1028 -1033.

Doolittle, D. (1991). Clinical ethnography of lacunar stroke: Implications for acute care. Journal of Neuroscience and Nursing, 23, 235-240.

Folstein, M. F., Folstein, S. E., \& McHugh, P. R. (1975). Mini-mental state. A practical method for grading the cognitive state of patients for the clinician. Journal of Psychiatry Research, 12, 189-198.

Forster, A., Smith, J., Young, J., Knapp, P., House, A., \& Wright, J. (2001). Information provision for stroke patients and their caregivers. The Cochrane Database of Systematic Reviews, 3, CD001919.

Glaser, B. G., \& Strauss, A. L. (1967). The Discovery of Grounded Theory. Strategies for Qualitative Research. Chicago: Aldine Publishing.

Greenhagh, T., \& Taylor, R. (1997). How to read a paper: Papers that go beyond numbers (qualitative research). British Medical Journal, 315, 740-743.

Grbich, C. (2007). Qualitative data analysis: An introduction. London: Sage Publications. 
Hammell, K. W. (2006). Perspective on Disability and Rehabilitation: Contesting assumptions and challenging practice. London: Sage Publications.

Hankey, G. J., Jamrozik, K. J., Broadhurst, R. J., \& Anderson, C. S. (2002). Long-term disability after first ever stroke and related prognostic factors in the Perth Community Stroke Study. Stroke, 33, 1034-1040.

Hodics, L., Cohen, S., \& Cramer, C. S. (2006). Functional imaging of intervention effects in stroke motor rehabilitation. Archives of Physical Medicine and Rehabiliation, 87, 36-42.

Hopman, W. M., \& Verner, J. (2003). Quality of life during and after inpatient stroke rehabilitation. Stroke, 34, 801-805.

Kauffman, S. R. (1998). Stroke rehabilitation and the negotiation of identify. In S. Reinharz \& G. D. Rowles (Eds.), Qualitative gerontology (pp. 82-103). New York: Springer Publishing.

Krefting, L. (1991). Rigor in qualitative research: The assessment of trustworthiness. American Journal of Occupational Therapy, 45, 214-222.

Law, M., Baptiste, S., \& Mills, J. (1995) Client-centred practice: What does it mean and does it make a difference? Canadian Journal of Occupational Therapy, 62, 250-257.

Lincoln, Y., \& Guba, E. (1985). Naturalistic inquiry. Beverly Hills, CA: Sage Publications.

McKevitt, C., Redfern, J., Mold, F., \& Wolfe, C. (2004). Qualitative studies of stroke: A systematic review. Stroke, 35, 1499-1505.

National Stroke Foundation. (2006). National Stroke Foundation website. Retrieved on Sept 12, 2006, from www.strokefoundation. com.au/.

O’Connell, B., Hanna, B., Penney, W., Pearce, J., Owen, M. \& Warelow, P. (2001). Recovery after stroke: A qualitative perspective. Journal of Quality in Clinical Practice, 21, 120-125.

Pound, P., Bury, M., Gompertz, P., \& Ebrahim, S. (1995). Stroke patients' views on their admission to hospital. British Medical Journal, 311, 18-22.

Pound, P., Gompertz, P., \& Ebrahim, S. (1998). A patient-centred study of the consequences of stroke. Clinical Rehabiliation, 12, 255-264.

Pope, C., Ziebland, S., \& Mays, N. (1995). Reaching the parts other methods cannot reach: An introduction to qualitative methods in health and health services research. British Medical Journal, 311, 42-45.

Rothwell, P., Coull, A., Giles, M., Howard, S., Silver, L., Bull, L., et al. (2004). Change in stroke incidence, mortality, case-fatality, severity, and risk factors in Oxfordshire, UK from 1981 to 2004 (Oxford Vascular Study). The Lancet, 363, 1925-1933.

Sinha, S., \& Warburton, E. A. (2000). The evolution of stroke units towards a more intensive approach. Quality Journal Medicine, 93, 633-638.

Strauss, A. L., \& Corbin, J. (1998). Basics of qualitative research: Techniques and procedures for developing grounded theory (2nd ed.). Thousand Oaks, CA: Sage Publications.

Sturm, J., Donnan, G., Dewey, H. M., Macdonell, R., Gilligan, A. K., \& Thrift, A. G. (2004). Determinants of handicap after stroke: The North East Melbourne Stroke Incidence Study (NEMESIS). Stroke, 35, 715-720.

Sulter, G., Steen, C., \& De Keyser, J. (1999). Use of the Barthel Index and Modified Rankin Scale in acute stroke trials. Stroke, 30, 15381541.

White, J., Alston, M., Marquez, J., Sweetapple, A., Pollack, M., Attia, J., et al. (2007). Community-dwelling stroke survivors: Function is not the whole story with quality of life. Archives of Physical Medicine and Rehabilitation, 88, 1140-1146.

White, J., Magin, P, Attia, J., Pollack, M., Sturm, J., \& Levi, C. (2008). Exploring post stroke depression: A qualitative study. Archives of Physical Medicine and Rehabilitation, 89, 1701-1707.

White, J., Magin, P., Mackenzie, L., \& Pollack, M. (2008). “I can't”: The occupational experience of stroke survivors in a community setting. A qualitative study. Occupational Therapy Journal of Research, 28,160-167.

Wilcock, A. (1998). Reflections on doing, being and becoming. Canadian Journal of Occupational Therapy, 65, 248-256.

Wiles, R., Pain, H., Buckland, S., \& McLellan, L. (1998). Providing appropriate information to patients and carers following a stroke. Journal of Advanced Nursing, 28, 794-801.

Yoon, S., \& Byles, J. (2002). Perceptions of stroke in the general public and patients with stroke: A qualitative study. British Medical Journal, 324, 1065.

Yoon, S., Heller, R., Levi, C., Wiggers, J., \& Fitzgerald, P. E. (2001). Knowledge of stroke risk factors, warning symptoms, and treatment among an Australian urban population. Stroke, 32, 1926-1930.

Zemke, R., \& Clark, F. (Eds.). (1996). Occupational science: The evolving discipline. Philadelphia: F. A. Davis.

\section{Authors}

Jennifer H. White, BAS (OT) is Post Acute Research Manager with the Hunter Stroke Service, Hunter New England Area Health Service, Locked Bag No. 1, Hunter Region Mail Centre, NSW, 2310, Australia. Telephone: +61 24921 4837. E-mail: jennifer.white@hnehealth.nsw.gov.au.

Parker Magin, $\mathbf{P h D}$, is from the Primary Health Care Research and Evaluation Development Program, Discipline of General Practice, Newbolds Building, University of Newcastle, University Drive, Callaghan, NSW, 2300, Australia.

Michael R. P. Pollack, FRACP, is Director of the Rankin Park Centre, Hunter New England Area Health Service, Rankin Park Centre, Lookout Rd, New Lambton, NSW, 2310, Australia.

\section{APPENDIX 1: Interview guide}

1. I would first like to ask you some questions about yourself?

2. Can you tell me about a typical fortnight before you had the stroke eg what you spent your time doing, the people you saw etc?

3. How has your life changed since your stroke?

4. How do you feel about these changes?

5. Can you tell me about your experiences during your hospital admission for stroke?

6. Can you tell me about your experience when you came home from hospital after your stroke?

7. In the ideal world what support would you like to see provided?

8. Have you ever sought out advice or information about living with stroke, or talked to anyone about it?

9. Would you say you have adjusted to having had stroke?

10. What does your future look like? 